\title{
The combination of dissimilar alleles of the $A \alpha$ and $A \beta$ gene complexes, whose proteins contain homeo domain motifs, determines sexual development in the mushroom Coprinus cinereus
}

\author{
Ursula Kües, ${ }^{1}$ Wendy V.J. Richardson, ${ }^{1}$ Anna M. Tymon, Effie S. Mutasa, Berthold Göttgens, ${ }^{1}$ \\ Stefan Gaubatz, Andreas Gregoriades, and Lorna A. Casselton ${ }^{1,2}$
}

School of Biological Sciences, Queen Mary and Westfield College, London E1 4NS, UK

\begin{abstract}
The $A$ mating-type factor is one of two gene complexes that allows mating cells of the mushroom Coprinus cinereus to recognize self from nonself and to regulate a pathway of sexual development that leads to meiosis and sporulation. We have identified seven $A$ genes separated into two subcomplexes corresponding to the classical $A \alpha$ and $A \beta$ loci. Four genes, one $\alpha$ and three $\beta$, all coding for proteins with a homeo domain-related motif, determine $A$-factor specificity; their allelic forms are so different in sequence that they do not cross-hybridize. It requires only one of these four genes to be heteroallelic in a cell to trigger $A$-regulated sexual development, and it is the different combinations of their alleles that generate the multiple $A$ factors found in nature. The other three genes cause no change in cell morphology and may regulate the activity of the four specificity genes.
\end{abstract}

[Key Words: Mating type; Coprinus; sexual development; sexual compatibility; homeo domain motifs]

Received October 28, 1991; revised version accepted February 13, 1992.

The mushroom Coprinus cinereus has a typical hymenomycete life cycle with two functionally distinct mycelial stages. A single sexual spore germinates to give a uninucleate-celled mycelium, the monokaryon, which is sexually sterile but produces abundant asexual spores, the oidia. For sexual reproduction, two compatible monokaryons must mate to give the fertile binucleatecelled mycelium, the dikaryon, which no longer produces oidia, but given the right temperature and light conditions, differentiates the fruiting bodies. Hyphal fusion is sufficient for mating and initiates the developmental pathway outlined in Figure 1. Nuclei are exchanged, and the donor nucleus in each case migrates through the established cells of the recipient hyphae, triggering the breakdown of cell septa until it reaches the hyphal tip cell. A complex mode of cell division then occurs that involves formation of a specialized structure at each septum, the clamp connection, through which one nucleus must pass. The clamp ensures the equal distribution of both genetically different nuclei to each daughter cell, because it is these two nuclei that will

\footnotetext{
${ }^{1}$ Present address: Department of Plant Sciences, University of Oxford, Oxford OX1 3RB, UK.

${ }^{2}$ Corresponding author.
}

eventually fuse and undergo meiosis in special cells on the undersurface of the mushroom (Casselton 1978).

The genes that determine monokaryon compatibility and regulate sexual development are the mating-type genes. Two species have been used as experimental models to study hymenomycete mating-type gene function, C. cinereus (Casselton 1978) and Schizophyllum commune (Raper 1983). From classic genetics it was established that in both fungi there were two unlinked genetic determinants that were called the $A$ and $B$ mating-type factors (see Raper 1966). These have multiple specificities (designated $A 1, A 2, A 3$, etc., and $B 1, B 2, B 3$, etc.) that must be different for dikaryon formation. As indicated in Figure 1, $A$ and $B$ independently regulate different steps in dikaryon morphogenesis; the $A$ factor described in this paper governs the synchronized division of the mated nuclei and the formation of the clamp cell, whereas clamp cell fusion and nuclear migration require different $B$ factors. There is no barrier to fusion of incompatible hyphae; and when only one factor is different, this leads to the isolated operation of the part of the sequence it regulates. When only $A$ is different, unfused clamp cells develop (Sweizynski and Day 1960). In C. cinereus and $S$. commune, it was shown by classic genetics that the $A$ factor derives its multiple specificities from two closely linked multiallelic genes termed $\alpha$ and 


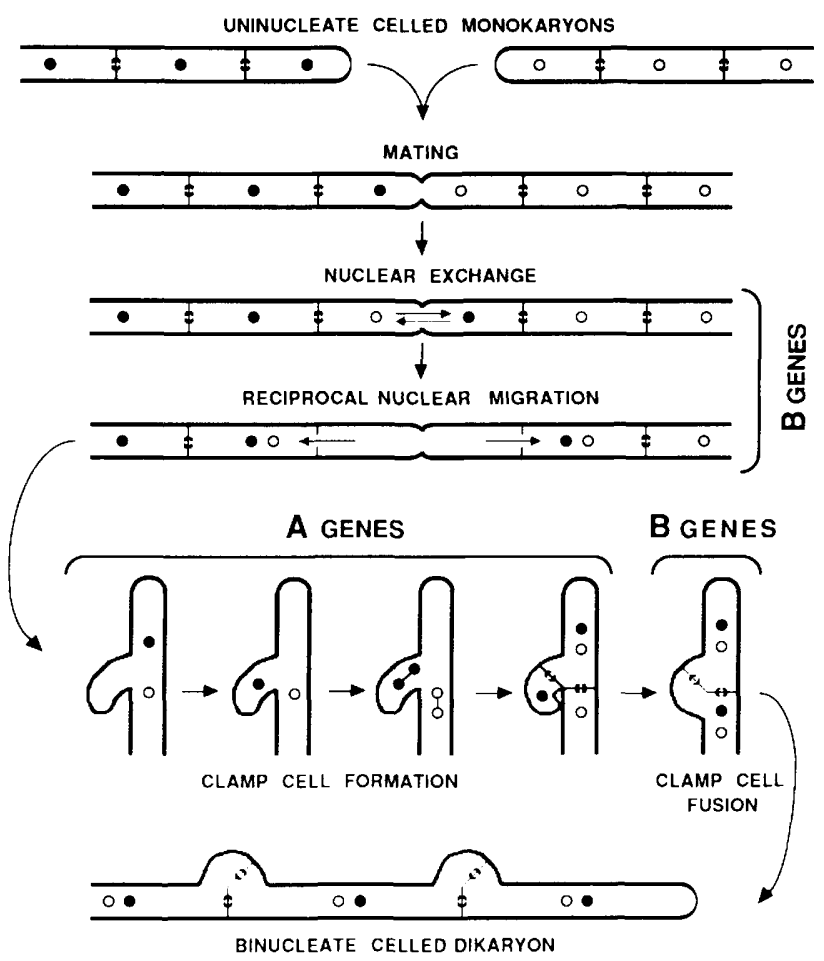

Figure 1. Regulation of dikaryon formation by the $A$ and $B$ mating-type genes of the mushroom $C$. cinereus.

$\beta$ (Papazian 1951; Raper et al. 1958, 1960; Day 1960). $\alpha$ and $\beta$ are functionally indistinguishable, every $A \alpha \beta$ allele combination is unique (i.e., $\alpha 1 \beta 1, \alpha 1 \beta 2, \alpha 2 \beta 1$, and $\alpha 2 \beta 2$ all have different specificities), and potentially large numbers of $A$ factors can be generated by recombination between a few alleles at each locus. The two $A$ loci of $C$. cinereus are very closely linked 0.07 map units|, and we have been able to isolate an entire $A$ factor on a single cosmid clone (Mutasa et al. 1990).

The multiallelic nature of the mushroom mating-type genes presents us with a fascinating problem in molecular recognition. On the one hand, there is self-nonself recognition in determining compatibility and, on the other hand, the regulation of common sets of genes that determine the differences between mated and unmated cells. The fact that there is no barrier to fusion of incompatible hyphae means that self-nonself recognition occurs intracellularly. In this paper we describe the molecular analysis of a cloned $A$ factor arbitrarily designated $A 42$. We identified seven genes, unevenly distributed into two subcomplexes corresponding to the $\alpha$ and $\beta$ loci. We show that specificity resides in four of these genes, one $\alpha$ and three $\beta$, and that the decision to initiate $A$-regulated development is a direct consequence of heteroallelism of one or more of these genes. The presence of homeo domain motifs in the proteins coded by the four specificity genes leads us to suggest that they code for transcription factors and that the cell senses a compatible $A$ interaction by its ability to produce at least one new regulatory protein from polypeptides coded by heteroalleles of these genes.

\section{Results}

Transcript analysis identifies seven A-factor genes

In our initial analysis of the cloned $A 42$ factor, we identified two genes that were both able to elicit $A$-regulated sexual development (formation of unfused clamp cells; Fig. 1) when introduced into host cells with different $A$ factors. Because we had shown that 0.1 map units represents a physical distance of $10 \mathrm{~kb}$ (Mutasa et al. 1990), we expected the $\alpha$ and $\beta$ loci to be $\sim 7.0 \mathrm{~kb}$ apart, which would correspond to the 0.07 map units determined by recombination analysis (Day 1960). The two genes identified were unexpectedly close together, however, and only $1.0 \mathrm{~kb}$ apart. A particularly puzzling feature was that the genes were embedded in $9.0 \mathrm{~kb}$ of $A 42$-specific DNA sequence that was shown to code for three different transcripts (Mutasa et al. 1990). These two facts suggested that the $A$ factor might be a larger complex of genes than predicted by genetic analysis and that we had identified only one of the $A$ loci.

To look for other $A$ genes, a detailed restriction map of the DNA sequence containing $A 42$ was constructed. Starting from the position of the genes identified previously, a sequence of $40 \mathrm{~kb}$ was examined for transcripts. A series of probes was chosen to cover this region and used to identify $A 42$ factor-specific mRNAs in Northern blots of poly(A) RNA isolated from an A42 monokaryon. Two discrete clusters of genes, one with two transcripts and one with five transcripts, were identified, which were both shown by transformation to promote clamp cell development (see below). These clusters were separated by a $7.0-\mathrm{kb}$ sequence from which no transcripts could be detected (Fig. 2) - a distance corresponding exactly to that predicted to separate the $\alpha$ and $\beta$ loci /see abovel.

The $A$ factor is flanked by two closely linked genes pab-1 and ade-8 (Day 1960); the $A 42$ factor was isolated by a chromosome walk from pab-1. By correlating the genetic map with the physical map shown in Figure 2, we can distinguish the two-gene cluster closer to pab-1 as the $\alpha$ locus and the five-gene cluster as the $\beta$ locus (Fig. 3). The two $\alpha$ genes, designated $\alpha 1$ and $\alpha 2$, have transcripts of 2.6 and $2.1 \mathrm{~kb}$, respectively, and are separated by $1.0 \mathrm{~kb}$ of noncoding sequence. At the $\beta$ locus, $\beta 1, \beta 2$, and $\beta 3$ with transcripts of $2.5,2.2$, and $2.45 \mathrm{~kb}$, respectively, are the three genes identified by Mutasa et al. (1990). $\beta 1$ and $\beta 2$ are separated by $1.0 \mathrm{~kb}$ of noncoding sequence from $\beta 3$. $\beta 4$ has a $2.5-\mathrm{kb}$ transcript and $\beta 5$ a smaller and relatively more abundant $1.1-\mathrm{kb}$ transcript. The direction of transcription in each case was determined by selective strand labeling of probes and confirmed by sequencing the 3 ' ends of cloned cDNAs (for details, see Materials and methods). $\beta 1$ and $\beta 5$ are transcribed in the opposite direction to the other five genes; the $\beta 4$ and $\beta 5$ transcripts overlap by 25 bases at their $3^{\prime}$ ends. Because the $A 42$ genes are the first $A$-factor genes 
Kües et al.

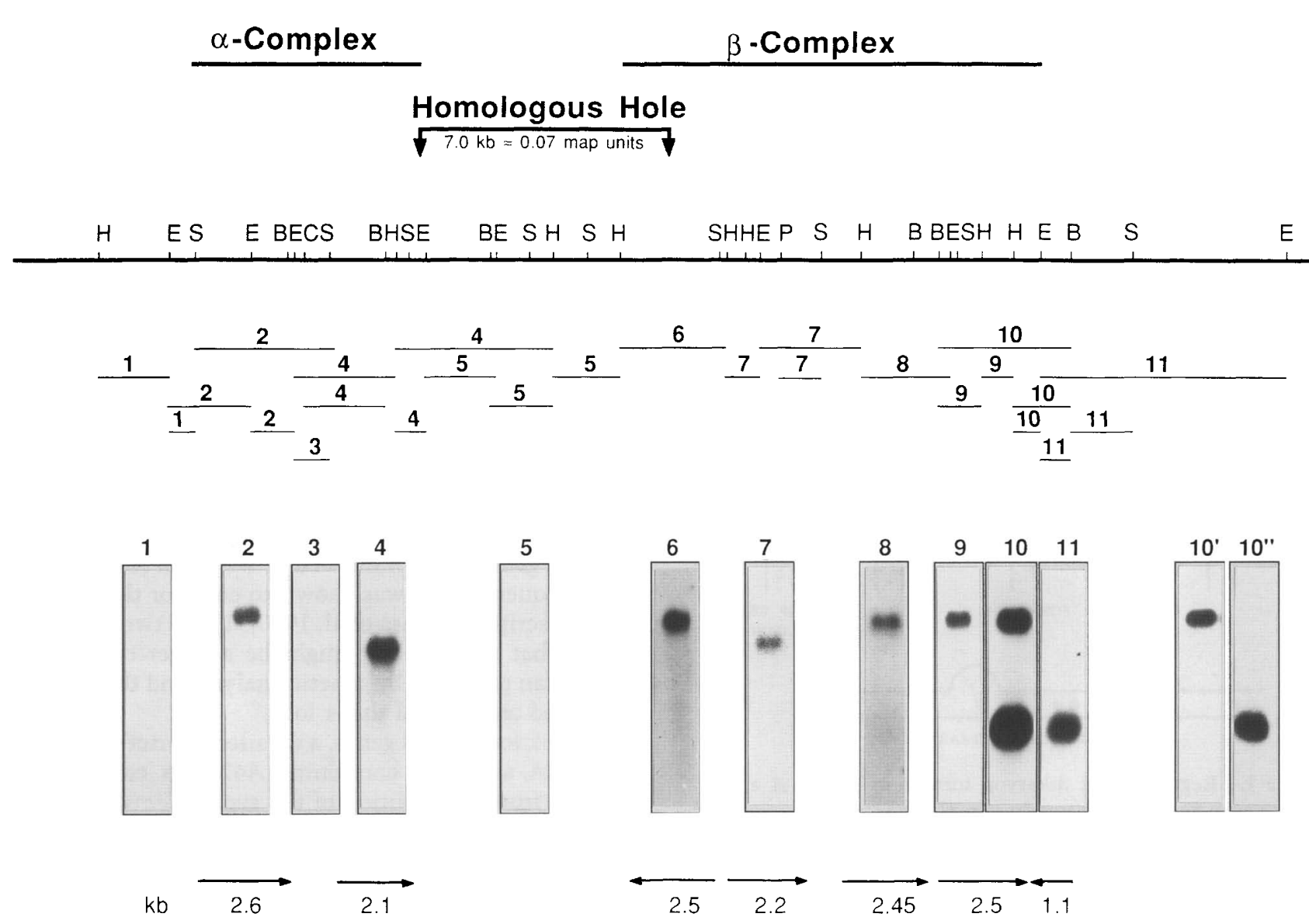

Figure 2. Physical map and corresponding transcript analysis of the $A 42$ mating-type region. Restriction sites relevant to this analysis are abbreviated as follows: (B) BamHI; (C) ClaI; (C) EcoRI; (H) HindIII; (P) PstI; (S) SalI. The chromosomal positions of the fragments used as hybridization probes in Northern blots (either subcloned in pBluescript or gel-purified fragments; see Materials and methods) are shown below the map. Numbers refer to the corresponding autoradiographs that show the transcripts detected by each of these probes. The arrows give the sizes and positions of transcripts with reference to the physical map and direction of transcription defined by selective strand labeling of pBluescript subclones. $\left(10^{\prime}, 10^{\prime \prime}\right)$ An example of using labeled single strands of plasmids pESM 6 and pUK8 to differentiate two overlapping transcripts. The relative positions of the two clusters of transcripts identified as the $\alpha$ and $\beta$ complexes are indicated above the map.

of $C$. cinereus characterized at the molecular level, we have given each gene the allele designation 1 (i.c., $\alpha 1-1$, $\alpha 2-1$, etc., in Fig. 3).

The genes of the A factor share no detectable sequence similarity

The lack of functional differentiation between $\alpha$ and $\beta$, shown by classic studies, suggested that one locus might be a duplication of the other (Raper 1966). Although we now show that there are more than two genes, the same argument could apply because of the obvious similarities in transcript sizes. If the genes have a common evolution we could expect to detect some sequence similarity and accordingly have looked for cross-hybridization. Five of the $A 42$ genes have been cloned separately as Sall fragments (pUK1-5; Fig. 4); a sixth SalI fragment cloned in pUK 6 contains the overlapping $\beta 4$ and $\beta 5$ genes. Each of the plasmids was used separately as hybridization probe against Sall-cut pUK plasmids (Fig. 4A). By cutting pUK6 with SalI and EcoRI, $\beta 4-1$ and $\beta 5-1$ were separated as close to the point of overlap as possible, and the fragments generated were tested for cross-hybridization in a separate experiment (Fig. 4B).

We could detect no cross-hybridization between any of the genes, suggesting that they are very different in nucleotide sequence.

\section{A mating-type specificity can be determined by four genes}

The introduction of a compatible $A$ factor into a haploid host by transformation has the same effect as a compatible mating; it elicits $A$-regulated clamp cell development (Mutasa et al. 1990; May et al. 1991). Each of the $A 42$ genes was tested separately to see whether it was sufficient to activate $A$-regulated development in five different $A$-factor backgrounds, $A 42$ (control), $A 3, A 5$, 


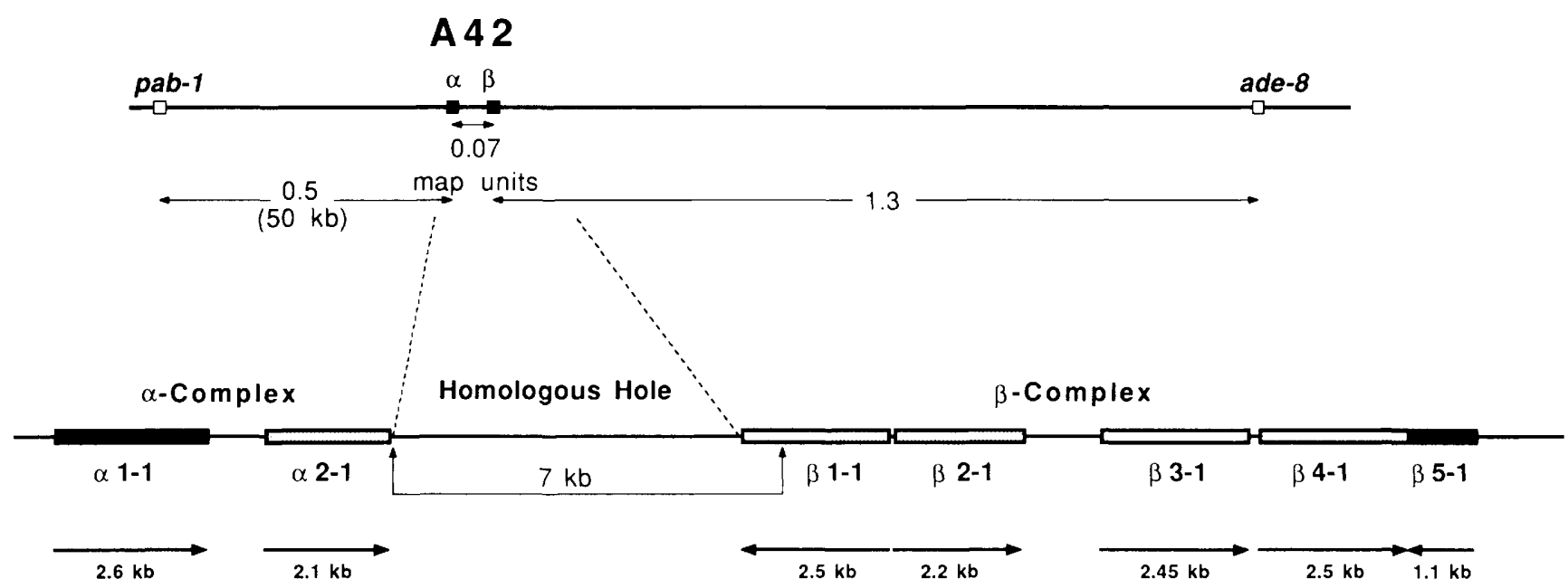

Figure 3. Correlation of the genetic map, based on recombination data of Day $(1960)$, and the physical map derived from this study. $\alpha 2-1, \beta 1-1, \beta 2-1$, and $\beta 4-1$ (stippled boxes) are the $A$-factor specificity genes that have alleles with unique sequence and that promote $A$-regulated sexual development when introduced by transformation into a host cell with a different allele of the gene. $\beta 3-1$ (open box) is a nonspecificity gene with unique allele sequences. $\alpha 1-1$ and $\beta 5-1$ (solid boxes) are nonspecificity genes that have common sequences in all $A$ factors tested (Fig. 6; Table 1). Sizes of transcripts and direction of transcription (Fig. 2) are indicated below the genes.

$A 6$, and $A 43$. No genetic data were available to indicate whether any of these factors share the same $\alpha$ or $\beta$ gene complex; Day's (1963) analysis showed only that $A 5$ and A6 have different $\alpha$ and $\beta$ alleles.

To select transformants, a cotransformation system based on tryptophan auxotrophy was used. Cotransformation occurs with $30-60 \%$ efficiency in $C$. cinereus (Mellon et al. 1987; Casselton and de la Fuente Herce 1989), but not all transforming DNA is expressed (Mellon and Casselton 1988). $\operatorname{Tr}^{+}$transformants were screened for clamp cell development. Where a negative result was recorded, 50-100 transformants were checked. The results of these tests are summarized in Table 1 . Four genes, $\alpha 2, \beta 1, \beta 2$, and $\beta 4$, individually elicited $A$-regulated clamp cell development when introduced into two hosts having either the $A 5$ factor or the A3 factor. The obvious morphologic change caused by introduction of these four $A 42$ genes into an $A 5$ host is illustrated in Figure 5. $\alpha 2-1$ did not promote clamp cell development in an $A 6$ host, but did in the $A 43$ host. $\beta 4-1$ failed to induce clamp cell development in both the $A 6$ and the $A 43$ hosts. As expected, none of the $A 42$ genes elicited clamp cell development when introduced into the $A 42$ host. The $\alpha 1-1, \beta 3-1$, and $\beta 5-1$ genes caused no detectable phenotypic change in any of the hosts. Because we know the precise location of the $3^{\prime}$ ends of the transcripts of each gene, we are confident that the fragments used for transformation (Sall fragments of 4.2, 3.55 , and $4.8 \mathrm{~kb}$ ) are large enough to contain the entire coding sequence together with $\sim 500 \mathrm{bp}$ of $5^{\prime}$-flanking sequence. This transformation analysis has allowed us to distinguish at least two functionally distinct classes of genes in the $A$ factor. The genes that promote clamp cell development clearly determine $A$-factor specificity, and we now refer to these as the specificity genes.
A
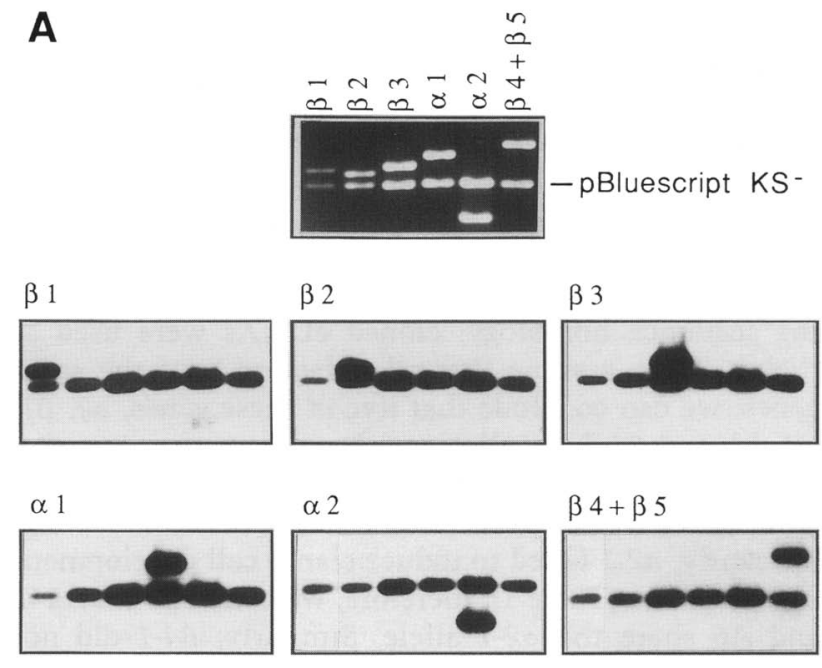

B

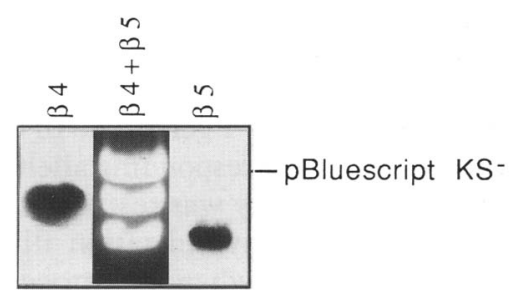

Figure 4. Cross-hybridization analysis of $A 42$ factor genes. $(A)$ Plasmids pUK1-6 were cut with Sall to release the subcloned genes, and each plasmid was then used individually as probe to the same Southern filter. $\beta 1, \beta 2$, etc., refer to the respective genes present in each lane and to the corresponding autoradiograph obtained using the cloned gene as hybridization probe. $|B|$ pUK6 cut with SalI and EcoRI to release $\beta 4$ and $\beta 5$ on separate fragments and corresponding hybridization data. 
Table 1. Identification of the four A42-factor specificity genes that promote A-regulated clamp cell development by DNA-mediated transformation into hosts with different A factors

\begin{tabular}{|c|c|c|c|c|c|c|c|}
\hline \multicolumn{3}{|c|}{$\alpha$-Complex } & \multicolumn{5}{|c|}{$\beta$-Complex } \\
\hline A42 gene & $\alpha 1-1$ & $\alpha 2-1$ & $\beta 1-1$ & $\beta 2-1$ & $\beta 3-1$ & $\beta 4-1$ & $\beta 5-1$ \\
\hline \multicolumn{8}{|c|}{ Host $A$ factor } \\
\hline$A 3$ & - & + & + & + & - & + & - \\
\hline$A 5$ & - & + & + & + & - & + & - \\
\hline$A 6$ & - & $\sim$ & + & + & - & $\sim$ & - \\
\hline$A 43$ & - & + & + & + & - & $\sim$ & - \\
\hline$A 42$ & - & $\sim$ & $\sim$ & $\sim$ & - & $\sim$ & - \\
\hline
\end{tabular}

Clamp cell development identifies a specificity gene $(+1 ;(\sim)$ failure of the specificity gene to promote clamp cells in this host resulting from the fact that the host $A$ factor has the same allele of the gene. $(-)$ The gene $\operatorname{did}$ not promote clamp cell development in any host.

\section{Most A genes have alleles with unique sequence}

An unexpected feature of the $\beta 1$ and $\beta 2$ genes described previously was the lack of cross-hybridization between cloned genes and their alleles in other $A$ factors (Mutasa et al. 1990). This analysis has now been extended to look for similarity between alleles of all seven genes and has allowed us to identify shared alleles in different $A$ factors. This is of special interest to the specificity genes.

Genomic DNAs of five strains having the $A$ factors $A 42$ (control), $A 3, A 5, A 6$, and $A 43$ were digested with $H$ indIII and probed separately with each of the $A 42$ genes, as shown in Figure 6. To avoid any possible flanking sequence homology, cloned cDNAs were used as probes. If we assume that all $A$ factors have the same genes, we can conclude that five of these genes, $\alpha 2, \beta 1$, $\beta 2, \beta 3$, and $\beta 4$, have alleles with unique sequence. $\alpha 2-1$ failed to hybridize to a corresponding $A$ gene in $A 3, A 5$, and $A 43$ DNA but hybridized strongly to $A 6$ DNA. Significantly, $\alpha 2-1$ failed to induce clamp cell development in an $A 6$ host (Table 1), therefore, we conclude that $A 42$ and $A 6$ share the $\alpha 2-1$ allele. Similarly, $\beta 4-1$ did not cross-hybridize to $A 3$ and $A 5$ DNA but did hybridize strongly to $A 6$ and $A 43$ DNA. $\beta 4-1$ failed to induce clamp cell development in an $A 6$ and an $A 43$ host, indicating that $A 42, A 6$, and $A 43$ share the $\beta 4-1$ allele. It is interesting to note that there is a restriction polymorphism within the $\beta 4-1$ gene. The $\beta 1-1$ allele showed faint hybridization to corresponding alleles in all other factors tested, but homology was restricted to the $3^{\prime}$ ends of the genes. The strong hybridization illustrated in Figure 6 was only detected when the probe was a short $0.3-\mathrm{kb}$ EcoRI-Pst fragment from the 3' end of $\beta 1-1$ cDNA. $\beta 2-1$ failed to hybridize to a corresponding $\beta 2$ gene in any other factor, and $\beta 3-1$ hybridized weakly to the allele in $A 43$ (the result of some homology at the $3^{\prime}$ end; data not shown).

From classic genetics we can expect different $A$ factors to share alleles of genes at either the $\alpha$ or the $\beta$ locus. It is not known from recombination studies whether any of the $A$ factors we have tested share the same $\alpha$ or $\beta$ alleles (Day 1963), but our hybridization and transformation data indicate that $A 6$ and $A 42$ share the same $\alpha$ specificity. These studies demonstrate that these two factors can also share alleles of a gene within the $\beta$ complex and still have a different overall specificity.

There are two genes, one in each cluster, that appear to be the same in all $A$ factors, $\alpha 1$ and $\beta 5$. As far as we can detect, there are no differences in the level of cross-hybridization between $\alpha 1$ genes in the different DNAs. For $\beta 5$, the corresponding gene in the $A 5$ factor was barely detectable, suggesting that there is some sequence variation among its alleles. We have, however, distinguished two classes of genes by this analysis: unique sequence genes $(\alpha 2, \beta 1, \beta 2, \beta 3$, and $\beta 4)$ and common sequence genes $(\alpha 1$ and $\beta 5)$.

The 7-kb region that separates the $\alpha$ and $\beta$ gene complexes (see Fig. 2) was shown to be homologous in all strains (Fig. 6), as expected by the reciprocal recombination that occurs between $\alpha$ and $\beta$ (Day 1960). We have called this region the homologous hole of the $A$ factor. It
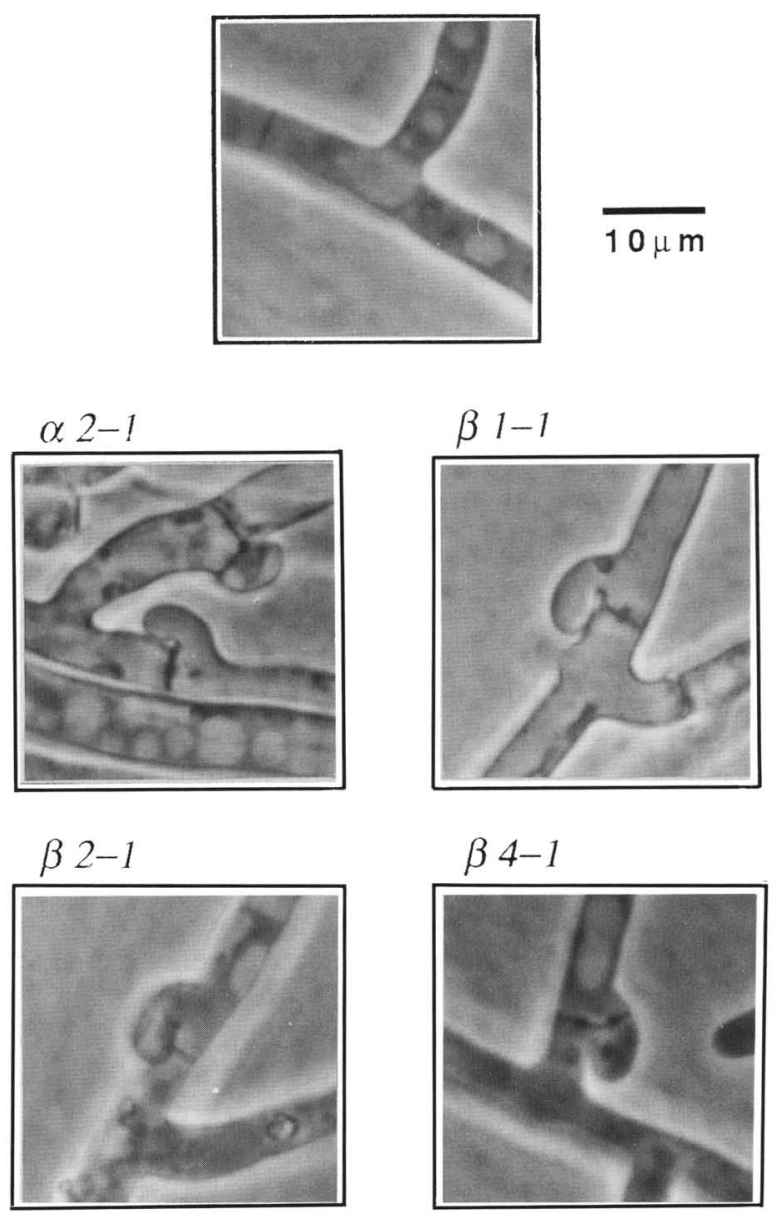

Figure 5. A-regulated clamp cell development elicited in an $A 5$ host cell by transformation with $A 42$ specificity genes. The untransformed $A 5$ monokaryon has only simple septa (top). Transformants with $\alpha 2-1, \beta 1-1, \beta 2-1$, and $\beta 4-1$ (below) all produce unfused clamp cells at each septum. 

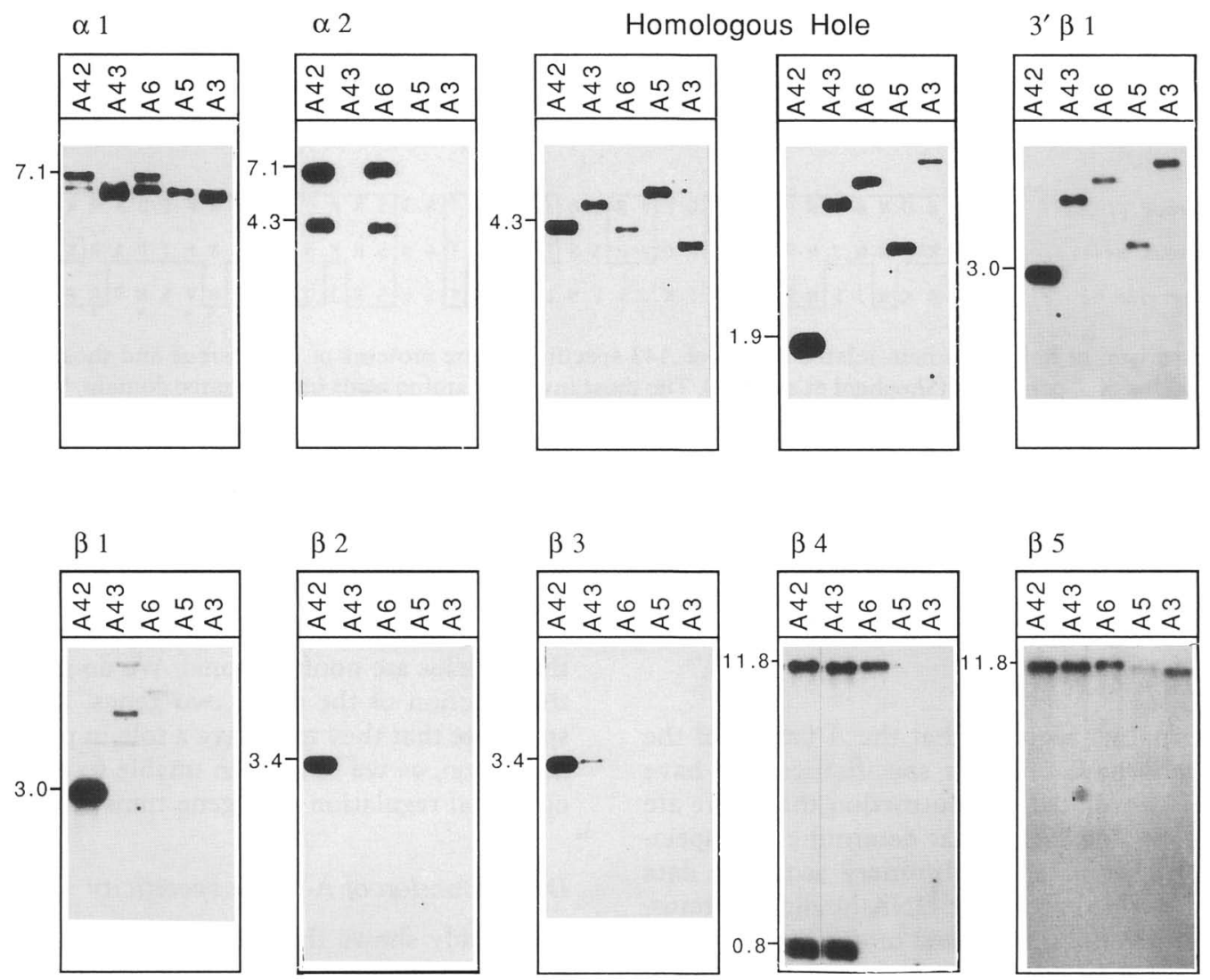

Figure 6. Genomic analysis of five different $A$ factors. cDNAs corresponding to each of the $A 42$ genes were used to probe $H i n d I I I-c u t$ genomic DNA $(5 \mu \mathrm{g})$ of monokaryons having the $A$ factors indicated for each lane on the autoradiographs illustrated. Size markers (in kb) indicate the HindIII fragments of the $A 42$ factor. The respective hybridization pattern obtained for each probe is indicated by the gene designation above the autoradiograph. The results of using two different probes are illustrated for $\beta 1,\left(\beta 1\right.$ and $\left.3^{\prime} \beta 1\right)$ to show the common $3^{\prime}$ sequence in all of its alleles. The noncoding sequence between the $\alpha$ and $\beta$ complexes was investigated using two genomic HindIII fragments of 4.3 and $1.9 \mathrm{~kb}$ cloned in pAMT6 and pAMT7. The two HindIII-BamHI fragments of pAMT7 (see physical map in Fig. 2) gave the same hybridization pattern as the whole plasmid (panel 3, top) confirming a length of $\sim 7.0 \mathrm{~kb}$ of homologous DNA constituting the homologous hole.

is homologous because all $A$ factors share this DNA sequence and a hole, from the point of view that we cannot detect any transcripts from it.

The A-factor specificity gene proteins contain a homeo domain-related motif

Although the complete sequences of the four $A 42 \mathrm{spec}-$ ificity genes are not yet available, preliminary data show that all encode proteins containing a putative DNAbinding domain, a homeo domain-related motif /Scott et al. 1989). The sequences of these domains have been compared with those present in the al and $\alpha 2$ matingtype proteins of Saccharomyces cerevisiae (Fig. 7). In the $\alpha 2-1$ and $\beta 2-1$ proteins, the homeo domain is more similar to that of $\mathbf{a} 1$, and in the $\beta 1-1$ and $\beta 4-1$ proteins it is more similar to that of $\alpha 2$.

\section{Discussion}

The genes we have described constitute an $A$ matingtype factor of the mushroom $C$. cinereus, a complex that determines compatibility in mating by regulating a developmental sequence that leads to fruit body development, meiosis, and sporulation. We have identified seven genes separated by $7 \mathrm{~kb}$ of noncoding homologous DNA sequence into two subcomplexes that correspond to the $\alpha$ and $\beta$ loci identified by classic recombination analysis. The organization of these genes is summarized in Figure 3. We have used sequence similarity and function as criteria for characterizing the $A$ genes, and this has enabled us to distinguish the three classes represented by the different boxes in Figure 3 . Four genes, one $\alpha$ and three $\beta$ (stippled boxes), determine $A$-factor specificity. The alleles of each gene have unique sequences. It is only when the same allele is present in two different $A$ factors that we can detect cross-hybridization (Fig. 6). Transformation data suggest that it requires only one of these genes to be made heteroallelic in a cell to promote $A$-regulated sexual development (i.e., $\alpha 2-1$, not present in $A 3, A 5$, or $A 43$, triggers clamp cell development when introduced into host cells with any one of these $A$ factors). A third gene with unique sequence alleles (open 

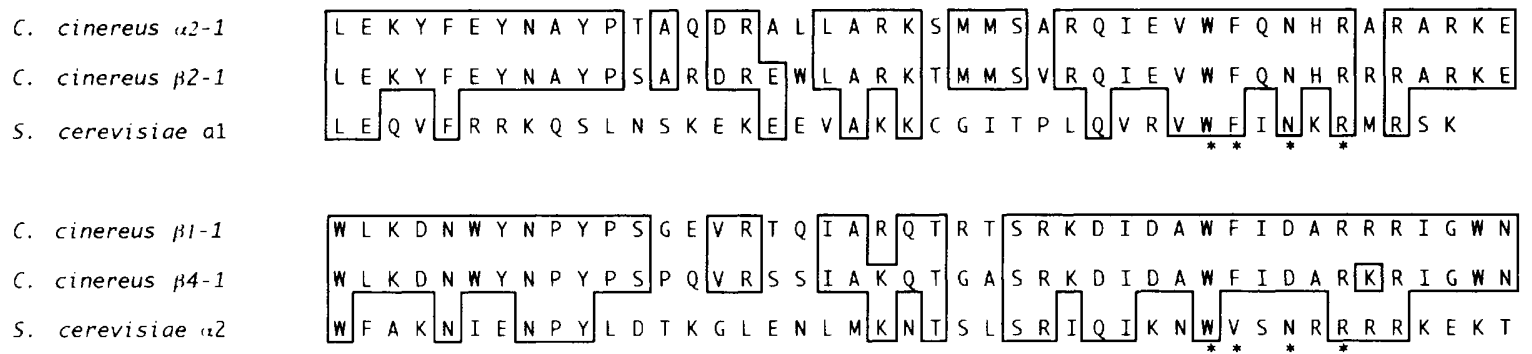

Figure 7. Comparison of homeo domain-related motifs of $A 42$ specificity gene proteins of C. cinereus and those of the al and $\alpha 2$ mating-type proteins of $S$. cerevisiae (Shepherd et al. 1984). The most invariant amino acids in the homeo domain, WF-N-R, which are found in the recognition helix (Scott et al. 1989), are marked by asterisks ( ${ }^{*}$ ).

box; Fig. 3) and two genes that are shared in all $A$ factors tested (solid boxes; Fig. 3) have been detected only by their transcripts; their functions are unknown.

\section{Function of the A-factor genes}

A compatible mating requires that the $A$ factors of the two mating cells have different specificities. We have shown by DNA-mediated transformation that there are four genes in the $A 42$ factor that determine this specificity, $\alpha 1, \beta 1, \beta 2$, and $\beta 4$. Preliminary sequence data show that these encode putative DNA-binding proteins, each with a homeo domain-related motif (Fig. 7), which suggests that they are transcription factors. The role of fungal mating-type proteins as transcription factors has been elegantly demonstrated in S. cerevisiae /for review, see Herskowitz 1989), and increasing evidence suggests that this is also truc in other species. The three polypeptides coded by the $S$. cerevisiae al, $\alpha 1$, and $\alpha 2$ genes all bind DNA sequences upstream of regulated genes to activate or repress a- and $\alpha$-specific haploid cell functions or as an al- $\alpha 2$ dimer to repress haploid functions in a diploid cell (see Herskowitz 1989). It is particularly relevant that al and $\alpha 2$ polypeptides have a homeo domainrelated motif (Shepherd et al. 1984; Scott et al. 1989). A similar motif is found in the mat1-P1 mating-type protein of Schizosaccharomyces pombe (Kelly et al. 1988) and in the multiallelic $b$ gene polypeptides of Ustilago maydis (Schulz et al. 1990). Preliminary sequence data for $A \alpha$ gene alleles of $S$. commune show that these alleles also encode proteins with homeo domain-related motifs (Ullrich et al. 1991).

Transcript analysis has enabled us to identify three other genes associated with the specificity genes. The tight clusters that these genes form strongly suggest that they are part of the $A$-factor complex. $\alpha 1$ and $\beta 5$ are the flanking genes and have a DNA sequence that appears to be at least partly homologous in the different $A$ factors examined, but there is no homologous flanking sequence between these genes and the adjacent specificity genes $\alpha 2$ and $\beta 4 . \beta 4$ and $\beta 5$ are transcribed in opposite directions with overlapping $3^{\prime}$ ends, and several long transcripts of $\alpha 1$, only identified by cDNA cloning (U. Kues, unpubl.), overlap the $5^{\prime}$ end of the $\alpha 2$ gene. The $\beta 3$ gene is particularly puzzling: As with the specificity genes, its alleles lack any detectable homology, but heteroallelism of this gene alone is insufficient to promote $A$-regulated sexual development. With so many specificity genes and their apparent redundancy, it is possible that some of their alleles are nonfunctional. We do not know, as yet, the function of the other two genes. It is tempting to speculate that they may have a role in post-translational activation, as we have been unable to detect any developmental regulation of $A$-gene transcription.

\section{Determination of A-factor specificity}

This study shows that it requires only one of the four $A$-factor specificity genes to be made heteroallelic for $A$-regulated sexual development to proceed. We conclude that nonself recognition and developmental regulation are jointly governed by the ability of a cell to synthesize polypeptides coded by heteroalleles of these genes. It is then logical to suggest that heteroallelic polypeptides can associate to form novel regulatory proteins not present in unmated cells. This idea is similar to models proposed by Schulz et al. (1990) to explain the recognition function of the $b$ gene of the hemibasidiomycete smut fungus $U$. maydis. A precedent for the interaction of different mating-type polypeptides is provided by $S$. cerevisiae, where the al- $\alpha 2$ dimer is a new regulatory protein that can only be formed in mated cells (see Herskowitz 1989; Dranginis 1990). It may be significant that al and $\alpha 2$ have dissimilar homeo domains (Shepherd et al. 1984). Two of the homeo domains in the C. cinereus $A 42$ mating-type proteins $(\alpha 2-1$ and $\beta 2-1)$ are more similar to that of al, and two $(\beta 1-1$ and $\beta 4-1)$ are more similar to that of $\alpha 2$ (Fig. 7). This could suggest that the interaction that triggers sexual development in $C$. cinereus is between nonallelic homeo domain proteins. Our transformation experiments do not rule out this possibility because of the large number of specificity genes present in each factor.

The problem of polypeptide recognition in basidiomycetes is more complex than in $S$. cerevisiae because there are multiple alleles, not just two alleles at the mating-type locus. In $U$. maydis there are $\sim 25$ alleles of the $b$ gene, which controls both mating compatibility and formation of the pathogenic dikaryon (Rowell and DeVay 1954; Puhalla 1968). These alleles are largely ho- 
mologous in sequence, and alleles encode polypeptides with only a variable amino-terminal domain (Kronstad and Leong 1990; Schulz et al. 1990). In both hymenomycetes studied, $C$. cinereus shown here and $S$. commune (Giasson et al. 1989), alleles of the $A$ mating-type genes do not cross-hybridize, indicating very different nucleotide sequences. This does not preclude some similarity at the protein level, as shown by preliminary sequence data for alleles of the same mating-type gene of $S$. commune (Ullrich et al. 1991). Allelic genes are different enough not to cross-hybridize, but their proteins may still have conserved regions necessary for polypeptide recognition. This leads to an important problem, highlighted in our study. With four specificity genes, apparently identical in function, how are polypeptides brought together by mating distinguished from those already present in the unmated cell? It seems likely that some of the specificity genes are redundant. It will require us to generate null mutants to demonstrate this, a difficult task in C. cinereus because homologous gene replacement by transforming DNA is extremely rare (Binninger et al. 1991).

\section{Multiple A-factor specificities}

Day (1963) identified $31 \mathrm{~A}$ factors in a sample of 33 independent isolates of $C$. cinereus. From this analysis it is predicted that $>160 \mathrm{~A}$ factors exist (Raper 1966). We have shown that four genes determine specificity and that different $A$ factors can share their alleles. If all allele combinations are possible, only four alleles of each gene are required to generate $256 \mathrm{~A}$ factors. It is unlikely, however, that these genes are easily reassociated in nature. Separation of the $\alpha 2$ gene into a separate subcomplex allows this to be recombined with all specificity genes in the $\beta$ complex, but the organization within the $\beta$ complex suggests that its genes are rarely recombined. Not only do alleles of the genes lack sequence similarity, but flanking sequences are also nonhomologous (Mutasa et al. 1990). Reciprocal recombination is possible only if a region of homology is presented by a shared $\beta$ allele. The only shared alleles detected in this study were $\beta 4-1$ and $\beta 5-1$. Because of their positions at the border of the complex, recombination within these genes would not recombine the other specificity genes to generate new $A$ factors.

Because of the close linkage of $\alpha$ and $\beta$, the only estimates of allele numbers at each locus are from a small survey of $10 \mathrm{~A}$ factors studied by Day (1963), which identified four $\alpha$ and five to seven $\beta$ alleles. Unfortunately, only two of the characterized factors $(A 5$ and $A 6)$ are still available. Day's studies lead us to expect at least four alleles of the $\alpha 2$ specificity gene. A molecular approach will be required to determine whether the three $\beta$ specificity genes are also multiallelic. The $A 43$ factor of $C$. cinereus used in this study has been cloned by May et al. (1991). The investigators provide evidence for three specificity genes in this factor. We have shown here that $A 43$ and $A 42$ share the allele of one of these ( $\beta 4-1)$ (Fig. 6). Better resolution of $A 43$ by transformation analysis has revealed one specificity gene at the $\alpha$ locus and two genes in addition to $\beta 4-1$ at the $\beta$ locus (U. Kües et al., unpubl.). As expected from the hybridization data (Fig. 6), all of these alleles are different from those present in $A 42$. Because both sets of specificity genes trigger $A$-regulated development in an $A 3$ host, we can conclude that at least two of the $\beta$ specificity genes are multiallelic.

This study shows that the $A$ mating-type factor is far more complex than predicted by classic genetics. With four different genes, all contributing a unique specificity, our analysis provides an insight into how such large numbers of different $A$ factors have developed in nature.

\section{Materials and methods}

C. cinereus strains include $A 42 B 42$ : JV6 wild type; LN1 18 ade-2 trp-1.1,1.6; $A 6 B 6$ : H9 wild type; LT2 trp-1.1,1.6; A5B6: H5 wild type; FA2222 trp-1.1,1.6; $A 3 B 1$ : C692 ade-3; 218 trp-1.1,1.6; A43B43: OK 130 ade-8; AT8 ade-8 trp-1.1,1.6. Media and methods for culturing $C$. cinereus have been described by Lewis (1961), with modifications summarized by Mutasa et al. (1990). The transformation procedure was based on that of Binninger et al. (1987), as modified by Casselton and de la Fuente Herce (1989). Plasmid pCc1001, containing the C. cinereus trp-1 gene (Binninger et al. 1987), and pDB1, containing the C. cinereus trp-3 gene (D.M. Burrows, T.J. Elliott, and L.A. Casselton, unpubl.), were used for cotransformation experiments with trp auxotrophic $C$. cinereus strains. Photographs of clamp cells were taken with a Zeiss photomicroscope using phase contrast.

\section{DNA manipulations}

Genomic DNAs of C. cinereus strains were prepared either by the method of Wu et al. (1983) or by the small-scale method of Zolan and Pukkila (1986). Routine cloning and plasmid amplification was in Escherichia coli strains XL-1 Blue [recAl, lac", endA1, gyrA96, thi, hsdR17, supE44, relA1, (F' proAB, lacl',

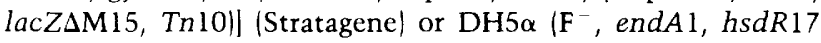

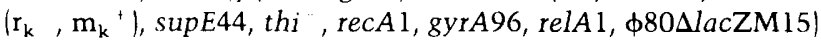
(BRL) using standard DNA techniques (Sambrook et al. 1989).

\section{Plasmids constructs with $\mathrm{C}$. cinereus DNA}

$\mathrm{pECl}, \mathrm{pECl} 2$, and $\mathrm{pECl} 6$ are recombinant clones from a cosmid library constructed in Lorist 2 and contain parts or the whole sequence of the $A 42$ mating-type factor (Mutasa et al. 1990). Gel-purified fragments or restriction digests of these cosmid clones were subcloned into the polylinker of either pBluescript/KS - ) or pUC13 (pBG-series) and used for restriction and hybridization analysis to map the $A 42 \alpha$ and $\beta$ loci and to complete the restriction map given earlier (Mutasa et al. 1990). (Compare Fig. 2 to localize subcloned fragments especially mentioned for transformation, hybridization, and sequencing experiments.)

pBluescript (KS - ) subclones of genomic fragments used for Coprinus transformations pAMTl contains $\beta 1-1$ on a $3.0-\mathrm{kb}$ HindIII fragment, and pESM1 contains $\beta 2-1$ on a $2.8-B a m H I-$ SalI fragment (Mutasa et al. 1990). pUK1, pUK2, and pUK4 pUK6 have genes $\alpha 1-1, \alpha 2-1, \beta 2-1, \beta 3-1$, and $\beta 5-1$ on Sall fragments of lengths $4.2,2.1,3.4,3.55$, and $4.8 \mathrm{~kb}$, respectively. pUK6 contains $\beta 5-1$, together with an inactive truncated copy of $\beta 4-1$ on a 4.8 -kb Sall fragment. pESM 2 contains the complete $\beta 4-1$ gene on a $4.0-\mathrm{kb}$ BamHI fragment. 
Subclones used for Northern analyses pAMT1, pUK1, pESM2, and the following plasmid subclones were used for Northern analyses. pUK7 contains a 2.9-kb EcoRI-HindIII fragment containing most of the $\alpha 2-1$ gene. pAMT6 and pAMT7 contain 4.0 and $1.9-\mathrm{kb} H$ HindIII fragments, respectively, which identify the noncoding sequence between the $\alpha$ and $\beta$ genes. pUK3 has a 3.5 -kb Sall fragment containing the $\beta 1-1$ gene. A $0.5-\mathrm{kb}$ HindIII and a $0.4-\mathrm{kb}$ HindIII-EcoRI fragment with the $5^{\prime}$ end of gene $\beta 2-1$ was subcloned after partial restriction of pCE12 to give pBG1. pBG2 contains a $2.9-\mathrm{kb}$ EcoRI-HindIII fragment with the $3^{\prime}$ end of gene $\beta 2-1$, and pBG3 contains a $2.5-\mathrm{kb}$ HindIII-EcoRI fragment with most of the $\beta 3-1$ gene sequence. pESM3 is a subclone of pBG2 containing a $1.2-\mathrm{kb}$ PstI-SalI fragment. pESM4, pESM5, pESM6, and pUK8 carry a $1.3-\mathrm{kb}$ BamHIHindIII fragment, a $1.0-\mathrm{kb}$ HindIII fragment, a $1.7-\mathrm{kb}$ HindIII$B a m$ HI fragment, and a 0.7-kb HindIII-EcoRI fragment, respectively, each with parts of the $\beta 4-1$ gene sequence. pUK9 has a 1.0-kb EcoRI-BamHI fragment carrying part of $\beta 5-1$.

pLACl was isolated from a plasmid genomic library of $C$. cinereus strain H9 constructed by Pukkila et al. (1984), using the $A 42 \alpha 2-1$ gene as hybridization probe. pLACl contains the two genes of the $A 6 \alpha$ locus. Because $A 6$ and $A 42$ have the same alleles of these two genes, fragments from pLACl subcloned into pBluescript $/ \mathrm{KS}-\mid$ could be used as gene probes in Northern hybridizations. pHH5 and $\mathrm{pHH} 7$ contain the $5^{\prime}$ and $3^{\prime}$ ends of the $\alpha 1-1$ gene cloned on 2.4-kb and 1.1-kb EcoRI fragments, respectively. pUK 10 contains part of the $\alpha 2-1$ gene on a $2.0-\mathrm{kb}$ ClaI-BamHI fragment.

Subclones used for Southern analysis pUK1-pUK6 were used to detect homology between different $A 42$ genes. cDNAs for all $A$-gene transcripts were subcloned from $\lambda \mathrm{gtl0}$ into pBluescript(KS -) with either the EcoRI or the BamHI sites of the $\lambda \mathrm{gt} 10$ adapter. These were used to detect homoallelic genes in genomic DNA digests. The length of the homologous hole was defined using gel-eluted fragments of pAMT6 and pAMT7.

\section{RNA isolation}

Strain JV6 was grown in liquid minimal medium, and total RNA was prepared using the guanidinium thiocyanate-CsCl step gradient procedure (Glisin et al. 1974; Sambrook et al. 1989), with the modification suggested by Chirgwin et al. (1979) of resuspending the pellet in $7.5 \mathrm{M}$ guanidinium hydrochloride after the ultracentrifugation step. Standard extractions were from 10 grams wet weight mycelium ground in $10 \mathrm{ml}$ of extraction buffer with a polytron homogenizer (Kinematica PT10/35). mRNA was selected using oligo(dT) cellulose (Pharmacia) as described by Sambrook et al. (1989). For Northern blotting, mRNA $(5 \mu \mathrm{g})$ was denatured at $55^{\circ} \mathrm{C}$ for $15 \mathrm{~min}$ with $17.5 \%$ formaldehyde and $50 \%$ formamide and electrophoresed on a $1 \%$ agarose gel containing $17.5 \%$ formaldehyde. An RNA ladder of $0.24-9.5 \mathrm{~kb}$ (BRL) was used to determine transcript sizes.

\section{Nucleic acid blots and hybridizations}

Gels prepared for Southern or Northern analyses were blotted onto Hybond- $\mathrm{N}$ membranes (Amersham) in $20 \times \mathrm{SSC}(3 \mathrm{M} \mathrm{NaCl}$, $0.3 \mathrm{M}$ sodium citrate). For Southern blots, hybridizations were performed overnight at $65^{\circ} \mathrm{C}$ as described by Mellon et al. (1987). Hybridizations of Northern blots and washes were performed as recommended for Hybond- $\mathrm{N}$ by the manufacturers. For autoradiography, filters were exposed to Fuji X-ray film. Filters for both Southern and Northern analyses were stripped (see manufacturers' instructions) and reused to allow direct size comparisons.
Gel-isolated DNA fragments or plasmid clones for Southern blots were labeled with $\left[\alpha^{-32}\right.$ P $]$ CTP using a nick-translation kit (BRL). High-activity hybridization probes for RNA blots were generated by labeling double-stranded DNA (dsDNA) or singlestranded DNA (ssDNA) with $\left[\alpha{ }^{-32} \mathrm{P}\right] \mathrm{CTP}(>3000 \mathrm{Ci} / \mathrm{mmole}$, Amersham) using a random primer kit (Boehringer). dsDNA probes used for Northern analyses, indicated in Figure 2 but not described above, were gel-purified restriction fragments of the cosmids or pUC13 and pBluescript(KS - ) subclones. To determine transcript directions, single-stranded DNAs were prepared from pBluescript|KS - ) subclones using the helper phage M13K07 (Sambrook et al. 1989), and labeled strands were generated using the Klenow fragment of $E$. coli DNA polymerase I and the M13 reverse primer (Ley et al. 1982; Sambrook et al. 1989).

\section{Construction of a cDNA library}

A $\lambda g t 10$ cDNA library was contructed with mRNA isolated from wild-type strain JV6 and the cDNA synthesis system plus and cDNA cloning system- $\lambda$ gt 10 from Amersham (RPN 1256 and RPN 1257) using the recommended $E$. coli strain NM514 $\left[\right.$ hsdR514 $\left.\left.\left|\mathrm{r}_{\mathrm{k}} \quad \mathrm{m}_{\mathrm{k}}\right| \operatorname{argH}, \operatorname{galE}, \operatorname{galX}, \operatorname{Str} A, \operatorname{lycB} 7^{*}(\mathrm{Hfl})^{+}\right)\right]$as host. The library was screened with pBluescript(KS-) subclones. Screening of $10^{4}$ to $10^{5}$ plaques was needed to detect one copy of each gene.

\section{Sequencing}

All sequencing was performed with dsDNA of pBluescript(KS - ) or pUCl 3 subclones, ${ }^{35} \mathrm{~S}$-labeled ATP, the T7 polymerase kit of Pharmacia, and either the M13 universal or reverse primers. Homeo domain motifs (Fig. 7) were deduced from partial sequence data of cDNA clones. Transcription directions of all genes were confirmed by sequence analysis. cDNA 3 ' ends were located within specific genomic fragments identified by the transcript mapping analysis. The results of these analyses can be summarized with respect to the gene, the plasmid construct, sequence, and relative position on the restriction map shown in Figure 2: $\alpha 1-1$, pHH7, TCAGAATCCA *TTCTCACGGG, $0.25 \mathrm{~kb}$ upstream of the BamHI site; $\alpha 2-1$, pAMT6 6 EcoRI, TTGCATTTCA ${ }^{*}$ AGCACATTTC, $0.12 \mathrm{~kb}$ upstream of the EcoRI site; $\beta 1-1$, pAMT1, ATCCAGCATA *CTATCGACCA, $0.3 \mathrm{~kb}$ upstream of the HindIII site; $\beta 2-1$, pESM1, CCGATCGCTA *GTTGCAATAC, $0.2 \mathrm{~kb}$ downstream of the PstI site; $\beta 3-1, \mathrm{pBG} 3$, TCTGCCTCCA * GAGTGGCAAA, $0.5 \mathrm{~kb}$ upstream of the EcoRI site; $\beta 4-1$ and $\beta 5-1$, pUK8 CAAATACAAG* ${ }^{*}$ TAGACAAGCATTTGGGTTCCTTTCA *2. ATCCTCGTAG, $0.05 \mathrm{~kb}$ from the EcoRI site. The asterisk in each case indicates the polyadenylation site. ${ }^{* 1}$ marks the position of the pA site of the $\beta 5-1$ gene transcript in the opposite DNA strand, ${ }^{* 2}$ indicates the end of the $\beta 4-1$ transcript.

\section{Acknowledgments}

We thank Flora Banuett for her critical reading of the manuscript and her valuable discussion, and Georgiana May for the cloned $A 43$ factor. This work was supported by Science and Engineering Research Council grants GR/E90175 and GR/ F78781 to L.A.C. and studentship to A.M.T., and a Gatsby Charitable Foundation Sainsbury studentship to W.V.J.R.

The publication costs of this article were defrayed in part by payment of page charges. This article must therefore be hereby marked "advertisement" in accordance with 18 USC section 1734 solely to indicate this fact. 


\section{References}

Binninger, D.M., C. Skrzynia, P.J. Pukkila, and L.A. Casselton. 1987. DNA mediated transformation of the basidiomycete Coprinus cinereus. EMBO I. 6: 835-840.

Binninger, D.M., L. LeChevanton, C. Skrzynia, C.D. Shubkin, and P.J. Pukkila. 1991. Targeted transformation in Coprinus cinereus. Mol. Gen. Genet. 227: 245-251.

Casselton, L.A. 1978. Dikaryon formation in higher basidiomycetes. In The filamentous fungi (ed. J.E. Smith and D.R. Berryl, vol. 3, pp. 275-297. Edward Arnold, London, UK.

Casselton, L.A. and A. de la Fuente Herce. 1989. Heterologous gene expression in the basidiomycete fungus Coprinus cinereus. Curr. Genet. 16: 35-40.

Chirgwin, J.M., A.E. Przybyla, R.J. MacDonald, and W.J. Rutter. 1979. Isolation of biologically active ribonucleic acid from sources enriched in ribonuclease. Biochemistry 18: 52945299.

Day, P.R. 1960. The structure of the $A$ mating type locus in Coprinus lagopus. Genetics 45: 641-650.

- 1963. The structure of the $A$ mating type factor in Coprinus lagopus: Wild alleles. Genet. Res. Camb. 4: 323-325.

Dranginis, A.M. 1990. Binding of yeast $\mathbf{a} 1$ and $\alpha 2$ as a heterodimer to the operator DNA of a haploid-specific gene. Nature 347: 682-685.

Giasson, L., C.A. Specht, C. Milgrim, C.P. Novotny, and R.C. Ullrich. 1989. Cloning and comparison of $A \alpha$ mating-type alleles of the basidiomycete Schizophyllum commune. Mol. Gen. Genet. 218: 72-77.

Glisin, V.R., R. Crkvenjakov, and C. Byus. 1974. Ribonucleic acid isolated by caesium chloride centrifugation. Biochemistry 13: 2633-2637.

Herskowitz, I. 1989. A regulatory hierarchy for cell specialisation in yeast. Nature 342: 749-757.

Kelly, M., J. Burke, M. Smith, A. Klar, and D. Beach. 1988. Four mating-type genes control sexual differentiation in the fission yeast. $E M B O / .7: 1537-1547$.

Kronstad, J.W. and S.A. Leong. 1990. The $b$ mating-type locus of Ustilago maydis contains variable and constant regions. Genes \&) Dev. 4: 1384-1395.

Lewis, D. 1961. Genetical analysis of methionine suppressors in Coprinus. Genet. Res. 2: 141-155.

Ley, T.J., N.P. Anagnou, G. Pepe, and A.W. Nienhuis. 1982. RNA processing errors in patients with $\beta$-thalassemia. Proc. Natl. Acad. Sci. 79: 4775-4779.

May, G., L. Le Chavanton, and P.J. Pukkila. 1991. Molecular analysis of the Coprinus cinereus mating type $A$ factor demonstrates an unexpectedly complex structure. Genetics 128: $529-538$.

Mellon, F.M. and L.A. Casselton. 1988. Transformation as a method of increasing gene copy number and expression in the basidiomycete Coprinus cinereus. Curr. Genet. 14: 451456.

Mellon, F.M., P.F.R. Little, and L.A. Casselton. 1987. Gene cloning and transformation in the basidiomycete fungus Coprinus cinereus: Isolation and expression of the isocitrate lyase gene (acu-7). Mol. Gen. Genet. 210: 352-357.

Mutasa, E.S., A.M. Tymon, B. Göttgens, F.M. Mellon, P.F.R. Little, and L.A. Casselton. 1990. Molecular organisation of an $A$ mating type factor of the basidiomycete fungus Coprinus cinereus. Curr. Genet. 18: 223-229.

Papazian, H.P. 1951. The incompatibility factors and a related gene in Schizophyllum commune. Genetics 36: 441-459.

Puhalla, J.E. 1968. Compatibility reactions on solid medium and interstrain inhibition in Ustilago maydis. Genetics 60: 461474.
Pukkila, P.J., B.M. Yashar, and D.M. Binninger. 1984. Analysis of meiotic development in Coprinus cinereus. Controlling events in meiosis. Symp. Soc. Exp. Biol. 38: 177-194.

Raper, C.A. 1983. Controls for development and differentiation of the dikaryon in Basdiomycetes. In Secondary metabolism and differentiation in fungi (ed. J.W. Bennett and A. Ciegler), pp. 195-238. Marcell Dekker, New York.

Raper J.R., M.G. Baxter, and A.H. Ellingboe. 1960. The genetic structure of the incompatibility factors of Schizophyllum commune: The A factor. Proc. Natl. Acad. Sci. 46: 833-842.

Raper, J.R. 1966. Genetics of sexuality in higher fungi. The Ronald Press Company, New York.

Raper J.R., M.G. Baxter, and R.B. Middleton. 1958. The genetic structure of the incompatibility factors in Schizophyllum commune. Proc. Natl. Acad. Sci. 44: 889-900.

Rowell, J.B. and J.E. DeVay. 1954. Genetics of Ustilago zeae in relation to basic problems of its pathogenicity. Phytopathology 44: 356-362.

Sambrook, J., E.F. Fritsch, and T. Maniatis. 1989. Molecular cloning: A laboratory manual. Cold Spring Harbor Laboratory Press, Cold Spring Harbor, New York.

Schulz, B., F. Banuett, M. Dahl, R. Schlesinger, W. Schäfer, T. Martin, I. Herskowitz, and R. Kahmann. 1990. The $b$ allele of $U$. maydis, whose combinations program pathogenic development, code for polypeptides containing a homeodomainrelated motif. Cell 60: 295-306.

Scott, M.P., J.W. Tamkum, and G.W. Hartzell III. 1989. The structure and function of the homeodomain. Biochim. Biophys. Acta 989: 25-48.

Shepherd, J.C.W., W. McGinnis, A.E. Carrasco, E.M. DeRobertis, and W.J. Gehring. 1984. Fly and frog homeo domains show homologies with yeast mating type regulatory proteins. Nature 310: 70-71.

Sweizynski, K.M. and P.R. Day. 1960. Heterokaryon formation in Coprinus lagopus. Genet. Res. Camb. 1: 114-128.

Ullrich, R.C., C.A. Specht, M.M. Stankis, H. Yang, L. Giasson, and C.P. Novotny. 1991. Molecular biology of mating-type determination in Schizophyllum commune. In Genetic engineering, principles and methods (ed. J.K. Setlow), vol. 13, pp. 279-306. Plenum Press, New York.

Wu, M., J. Cassidy, and P.J. Pukkila. 1983. Polymorphisms in DNA of Coprinus cinereus. Curr. Genet. 77: 385-392.

Zolan, M.E. and P.J. Pukkila. 1986. Inheritance of DNA methylation in Coprinus cinereus. Genetics 120: 379-387. 


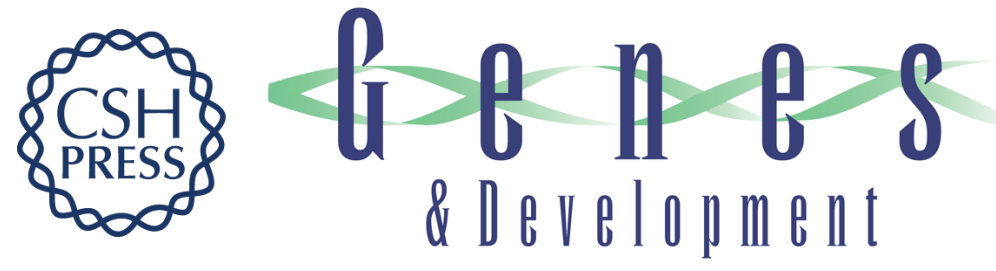

\section{The combination of dissimilar alleles of the A alpha and $A$ beta gene complexes, whose proteins contain homeo domain motifs, determines sexual development in the mushroom Coprinus cinereus.}

U Kües, W V Richardson, A M Tymon, et al.

Genes Dev. 1992, 6:

Access the most recent version at doi:10.1101/gad.6.4.568 $\begin{array}{ll}\text { References } & \begin{array}{l}\text { This article cites } 30 \text { articles, } 8 \text { of which can be accessed free at: } \\ \text { http://genesdev.cshlp.org/content/6/4/568.full.html\#ref-list-1 }\end{array}\end{array}$

License

Email Alerting Service

Receive free email alerts when new articles cite this article - sign up in the box at the top right corner of the article or click here.

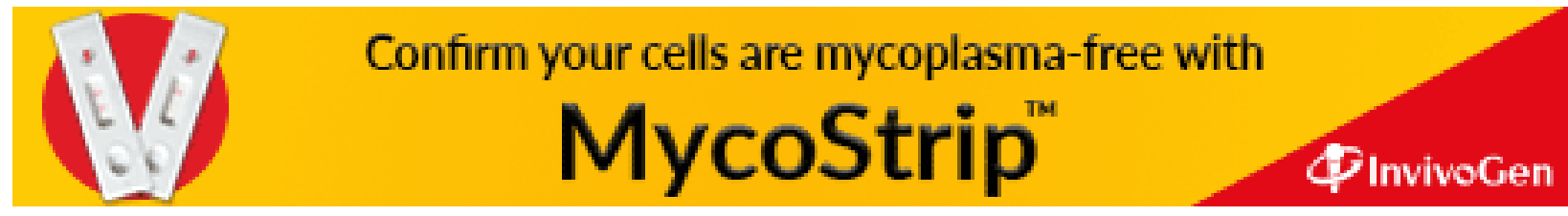

